\title{
Do individual cognitions mediate the association of socio-cultural and physical environmental factors with adolescent sports participation?
}

\author{
Klazine van der Horst ${ }^{1,2, *}$, Anke Oenema ${ }^{1}$, Saskia J te Velde ${ }^{3}$ and Johannes Brug ${ }^{3}$ \\ 'Department of Public Health, Erasmus University Medical Center, Rotterdam, The Netherlands: ${ }^{2}$ ETH Zurich, \\ Institute for Environmental Decisions (IED), Consumer Behavior, Universitaetstrasse 22, CHN H75.3, CH-8092 \\ Zurich, Switzerland: ${ }^{3}$ EMGO Institute for Health and Care Research, VU University Medical Center, Amsterdam, \\ The Netherlands
}

Submitted February 2009: Accepted May 2010

\begin{abstract}
Objective: To examine the associations of perceived physical environmental factors (availability of physical activity (PA) attributes at home, PA facilities in the neighbourhood, neighbourhood pleasantness and safety) and social environmental factors (parental sports behaviour and parental rule regarding sports participation) with adolescent leisure-time sports participation, and to explore whether the associations found were mediated by individual cognitions as derived from the theory of planned behaviour (TPB).

Design: Cross-sectional study.

Setting: In schoolyear 2005/2006 adolescents from seventeen schools in Rotterdam, the Netherlands, completed a questionnaire during school hours that included selfreported measures of leisure-time sports participation, perceived physical environmental factors and TPB variables. Information about parental sports behaviour and parental rule was obtained from a questionnaire that was completed by one parent of the adolescents.

Subjects: Data were collected from 584 adolescent-parent combinations.

Results: Data were analysed with multi-level logistic regression analyses. Availability of PA attributes at home $(\mathrm{OR}=1 \cdot 26)$, parents' sports behaviour $(\mathrm{OR}=2 \cdot 03)$ and parental rule $(\mathrm{OR}=1 \cdot 64)$ were associated with a higher likelihood of adolescents' leisure-time sports participation. These associations were partly mediated by attitude and intention.

Conclusions: Adolescents were more likely to engage in leisure-time sports when PA attributes were available at home, when parents participated in sports activities and had a rule about their offspring participation in sports activities. These associations were partly mediated by attitude and intention. These results suggest that parents can importantly promote sports participation among their offspring by making sports activities accessible and a family routine.
\end{abstract}

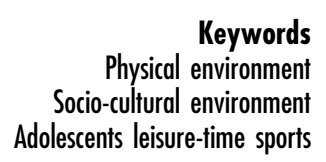

Keywords Socio-cultural environment Adolescents leisure-time sports
Insufficient physical activity (PA) is a risk factor for a range of chronic conditions, including obesity, among adults as well as adolescents ${ }^{(1,2)}$. Most adolescents do not meet the recommended minimum levels of engaging in at least $60 \mathrm{~min}$ of moderate-to-vigorous intensity PA each day ${ }^{(3-6)}$. Adolescents are a particularly important target group to improve PA levels since physically active adolescents are more likely to become active adults ${ }^{(7)}$. To be able to increase PA levels among adolescents, it is important to develop interventions that target the most important determinants of PA. In addition to individual cognitions such as attitude, subjective norm, perceived behavioural control and intention, as derived from the theory of planned behaviour (TPB), ${ }^{(8)}$ physical and social environmental factors may be important determinants of PA behaviour. Kremers et $a l^{(9)}$, in their Environmental Research framework for weight Gain prevention (EnRG), suggest that environmental factors may have both a direct and indirect association with behaviour. The direct association reflects a more automatic and unconscious effect of the environment on behaviours. The indirect influence suggests that environmental factors influence PA via the individual cognitions, e.g. environments that offer appealing and easily accessible opportunities for PA may result in more positive attitudes, perceived behavioural control and intentions towards leisure-time PA, which may result in 


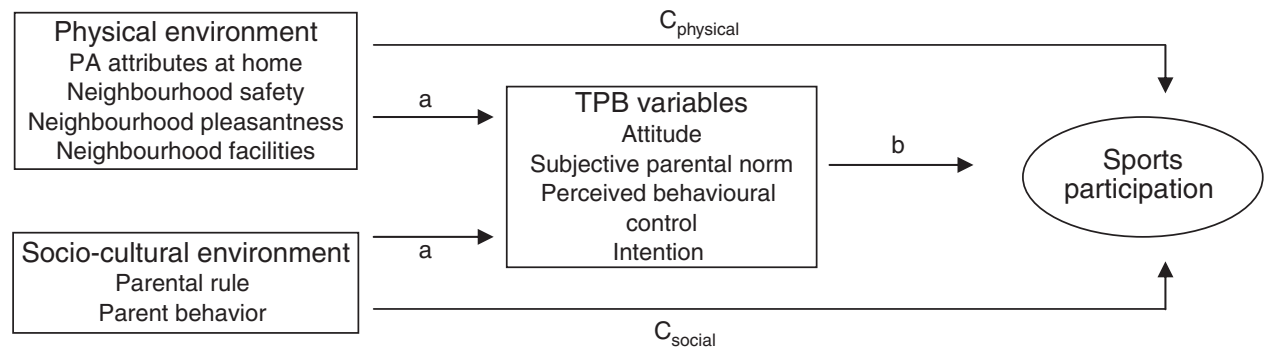

Fig. 1 Conceptual model of the direct and indirect association of physical and socio-cultural environmental factors (PA, physical activity; TPB, theory of planned behaviour)

higher PA levels. The TPB also assumes that the impact of various external variables such as physical and social environmental factors on behaviour is mediated by attitude, subjective norm, perceived behavioural control and intention.

Physical environmental factors, such as the availability and accessibility of PA opportunities, have received most attention in exploring environmental determinants of $\mathrm{PA}^{(9-11)}$. However, a recent review indicated that the evidence for the role of social environmental factors is stronger $^{(12-14)}$.

Earlier studies have found that among adults the association of perceived neighbourhood with walking was mediated by attitude ${ }^{(15)}$ and that associations of perceived neighbourhood aesthetics with walking were mediated by attitude and intention ${ }^{(16)}$. De Bruijn et al. ${ }^{(17)}$ found that the association of environmental aesthetics and distance to PA facilities on PA among adolescents was mediated by the intention to be physically active. Motl et $a l .{ }^{(18)}$ found that the association of equipment accessibility with adolescent girls' PA was mediated by selfefficacy. These previous studies indicate that some TPB variables may be more likely to serve as mediators in environment-behaviour relationships than others ${ }^{(17,19)}$, with the strongest evidence for attitudes as a potential mediating variable $^{(15-17,19,20)}$. Most previous studies have investigated mediation pathways for physical environmental factors.

The aim of the present study was to examine the associations between physical environmental factors (availability of PA attributes at home, PA facilities in the neighbourhood, neighbourhood pleasantness and safety) and social environmental factors (parents' own sports behaviour and parental rule about sports participation) with adolescents' leisure-time sports participation and to explore whether these associations are mediated by TPB variables (Fig. 1).

\section{Methods}

\section{Study design and sample selection}

Baseline data from the ENvironmental Determinants of Obesity in Rotterdam SchoolchildrEn (ENDORSE) study were used ${ }^{(21)}$ for which data were collected among adolescents in the first (12-13-year-olds) and third (14-15year-olds) years of secondary school. The Medical
Ethics Committee of Erasmus University Medical Center declared no objection to the project. Schools located in the Rotterdam area that participate in the Youth Monitor Rotterdam ( $n$ 56) were invited for participation in the ENDORSE study. Subsequently, a random sample of seventeen school locations was drawn from the pool of twenty-four schools that were willing to participate. On average, five classes per school location were randomly selected to participate in the study and 1668 adolescents and their parents were eligible for participation. In the baseline survey, 187 adolescents were absent during the questionnaire assessment. Owing to printing mistakes in the questionnaire, 120 records, including those from one entire school, had to be removed. The response rate for the parent questionnaire was $43 \%$, resulting in 584 adolescent-parent combinations. There were no data available on the parents and adolescents who did not participate in the study and examining response bias was therefore not possible. Compared to the data from the total adolescent sample, in the sample used for the present study adolescents with a non-Western ethnic background (36.6\% compared to $50 \cdot 5 \%$ ) and attending vocational schools ( $49 \cdot 1 \%$ compared to $56 \cdot 7 \%$ ) were under-represented.

\section{Procedure}

Parents received a letter announcing and explaining the ENDORSE study and could refuse participation of their child(ren) by sending a note to the adolescent's teacher. Between October 2005 and May 2006, the students completed the ENDORSE questionnaire in the classroom in the presence of a teacher and a trained research assistant within one school hour $(50 \mathrm{~min})$. The adolescents were handed a questionnaire with a pre-addressed and stamped envelope for completion by one of their parents. To increase the participation rates, five I-pods were raffled among the parent respondents and two reminders were sent to the parents.

\section{Measures}

\section{Leisure-time sports participation}

The relevant questions from the Activity Questionnaire for Adolescents and Adults were used to assess leisuretime sports activities ${ }^{(22)}$. The test-retest reliability of this 
questionnaire was moderate (intraclass correlations = $0 \cdot 30-0 \cdot 59)$ and validity with accelerometer data was low (Spearman's correlation coefficient $=0 \cdot 21$ for vigorous activities) ${ }^{(22)}$. No validity data were available on sports behaviour. First, the adolescents were asked to write in text boxes in a pre-structured format up to three sports activities that they had engaged in, in the past week. The adolescents were asked to write down the organized and unorganized sports they engaged in. Second, they had to tick on how many days in the past week (1-7d) they had engaged in this activity. Third, they had to indicate how long, on average, they participated in this activity per occasion, in an open answering format with text boxes to indicate the hours and minutes. The frequency and duration of the activities were multiplied, and then divided by the total number of days to provide the average $\mathrm{min} / \mathrm{d}$ spent doing leisure-time sports activities. As this variable was highly skewed and the distribution could not be improved through transformation, two categories were created: engaging in leisure-time sports activities for $<30 \mathrm{~min} / \mathrm{d}$ (coded as 0 ), or $\geq 30 \mathrm{~min} / \mathrm{d}$ (coded as 1 ). The cut-off of $30 \mathrm{~min}$ was chosen because adolescents are also involved in other activities such as active transport to school and because it was based on the Dutch PA recommendation that children and adolescents should engage in at least moderate activity for $60 \mathrm{~min} / \mathrm{d}^{(23)}$.

\section{Theory of planned behaviour variables}

Attitude, subjective parental norm, perceived behaviour control and intention were specifically assessed in relation to participation in leisure-time sports activities. All questions could be answered on a 5-point bipolar answering scale. Attitude was assessed with two items asking whether the adolescent considers sports and PA in leisure time as very good $(+2)$ or very bad $(-2)$ and as very pleasant $(+2)$ or very unpleasant $(-2)$. The mean item score (Cronbach's $\alpha=0 \cdot 79$, intraclass correlation $=0 \cdot 66$ ) for these items was calculated $^{(35)}$. Subjective norm was assessed with one item: 'if I engage in sports and PA in leisure time, my parents consider that as very good $(+2)$ or very bad $(-2)$ '. Perceived behaviour control was assessed with one item asking how easy or difficult it is to engage in sports and PA in leisure time with an answering scale ranging from very easy $(+2)$ to very difficult $(-2)$. Intention to perform the behaviour was assessed with a single item: 'Do you intend to engage in sports and PA in leisure time in the next 6 months?' with an answering scale ranging from Yes, I certainly do $(+2)$ to no, I certainly do not $(-2)$.

\section{Physical environmental variables}

We assessed the availability of PA opportunities at home by providing a list of ten sports 'attributes' (i.e. bicycle, dog, home trainer/treadmill, running shoes, stationary aerobic equipment, step aerobics, skates, balls, racquets and jumping rope). This list was translated from Sallis et al. ${ }^{(24)}$. The adolescents could tick which of these were available in their home. A score of PA attributes available at home was calculated by adding up the 'yes' responses to these questions. Perceived neighbourhood pleasantness was assessed with two questions: 'I think my neighbourhood provides a pleasant living environment', and 'I think my neighbourhood is attractive', which could be answered on a 5-point scale ranging from totally agree $(+2)$ to totally disagree $(-2)$. The mean item score (Cronbach's $\alpha=0 \cdot 78$, intraclass correlation $=0 \cdot 64$ ) of these two items was calculated. Perceived neighbourhood safety was assessed with four questions: 'There is a lot of traffic in my neighbourhood', 'It is unsafe to bicycle in my neighbourhood', 'I feel safe when I am in my neighbourhood', and 'It is unsafe to be outside in my neighbourhood', using the same 5-point answering scale format as neighbourhood attractiveness. The mean item score (Cronbach's $\alpha=0 \cdot 64$ ) of these four items was calculated. The perceived availability of PA facilities in the neighbourhood was assessed by asking the adolescents to indicate whether or not (yes/no answering format) there were parks, sports clubs, sports/playing grounds present in the neighbourhood where they lived. The yes responses were summed to form one score for these four items.

\section{Social environmental variables}

The parental rule about PA was assessed with one question in the questionnaire for parents: 'is it a rule in your household that your child has to participate in sports activities?' in a yes/no answering format. The parent's own sports behaviour was assessed in the questionnaire for parents with two questions assessing frequency and duration, using relevant questions from the Short QUestionnaire to ASsess Health-enhancing physical activity (SQUASH) questionnaire ${ }^{(25)}$. Spearman's correlation for overall reproducibility of the SQUASH was 0.58 (95\% CI $0 \cdot 36,0 \cdot 74$ ), and for correlations for the reproducibility of leisure-time sports it was $0 \cdot 90$. Spearman's correlation coefficient between activity monitor readings and the total activity score was $0 \cdot 45(95 \% \text { CI } 0 \cdot 17,0 \cdot 66)^{(25)}$. Frequency was assessed with: 'How many d/week do you engage in sports activities?' on a 7-point scale from $1=1 \mathrm{~d}$ /week to $7=$ every day. The duration was assessed with 'On a day that you participate in sports activities, how long do you do this on average?' and hours and minutes could be reported. The frequency and duration of the activities were multiplied, and then divided by the total number of days to provide the average min/d. As this variable was highly skewed, two categories were created: engaging in sports activities (coded as 1) and not engaging in sports activities.

\section{Demographics}

To establish ethnicity according to the Statistics Netherlands definition, the adolescents were asked to report in which country their parents were born ${ }^{(26)}$. Adolescents were considered to be from a Western ethnic background 
if both parents had been born in a European country, North America, Oceania, Indonesia or Japan. Based on the socio-economic and cultural position of immigrants in the Netherlands from Oceania, Japan and Indonesia (a former colony of the Netherlands), children from these immigrants were also included in the Western ethnic group. Adolescents were considered to be from a non-Western ethnic background if one or both parents had been born in other countries. The school type the adolescents attended was categorized into two levels: vocational schools and higherlevel secondary education (pre-academic). The schools provided educational level information. Age was determined based on the date of the measurements and the date of birth that were provided by the schools.

\section{Data analyses}

Possible multi-collinearity problems were examined with bivariate correlations and not encountered; all intercorrelations between predictors were below $0 \cdot 6$. Mediation analyses according to the suggestions of MacKinnon ${ }^{(27)}$ were used to identify the total effects, direct effects and mediated effects in the associations of physical environmental factors (availability of PA attributes at home, availability of PA facilities in the neighbourhood, perceived neighbourhood pleasantness and safety) and socio-cultural environmental factors (parents' sports behaviour and parental rule about sports participation) with adolescents' leisure-time sports participation ${ }^{(27)}$. To do so, we explored the associations between the environmental and TPB variables with multivariate linear regression analyses (step 1, path a in Fig. 1). Next, we examined whether the potential mediators from the TPB were associated with leisure-time sports, after adjustment for the environmental variables (step 2, path b in Fig. 1). The total effect of physical environmental and socio-cultural environmental factors on adolescents' leisure-time sports participation (step 3, path c), and after adjustment for the possible mediator, the direct effect of environmental variables on sports participation (step 4, path $c^{\prime}$ ) were examined in various models. As suggested by MacKinnon ${ }^{(27)}$ and also outlined by Cerin and MacKinnon ${ }^{(28)}$, a significant association between environmental variables (predictor variables) and sports participation (outcome variable) is not a requirement for mediation to occur, since the absence of an overall relationship may be due to suppression effects. Therefore, non-significant environmental factors were also included in the mediation analyses. Steps $2-4$ were examined by means of multi-level multivariate logistic regression analyses. All analyses were adjusted for gender, age, ethnicity and school level, as these are possible confounding factors. All analyses were performed with MLwiN version 2.02 (Centre for Multilevel Modelling, University of Bristol, Bristol, UK). A three-level structure was used to take into account that adolescents were nested within classes and classes within schools ${ }^{(29)}$. Owing to the dichotomous outcome variables, there are different scales across the (logistic) regression analyses that make it incorrect to use the 'difference-of-coefficients estimate' as an estimate of the mediation effect ${ }^{(28,30)}$. One solution to overcome this difference in scaling is to standardize the regression coefficients before mediation is estimated ${ }^{(30,31)}$. The standardized coefficients were subsequently used to estimate the proportion mediated $\left(\left(\mathrm{c}_{\text {standardized }}-\mathrm{c}^{\prime}\right.\right.$ standardized $\left.) / \mathrm{c}_{\text {standardized }}\right)$ and were additionally entered in the Sobel test ${ }^{(32)}$ to formally test the mediation effect.

\section{Results}

Sixty per cent of the adolescents reported participating in leisure-time sports for at least $30 \mathrm{~min} / \mathrm{d}$ (Table 1). The adolescents reported positive cognitions regarding leisuretime sports participation. On average, the adolescents reported having four of the listed PA attributes available at home (range: 0-10) and three PA facilities available in their neighbourhood (range: $0-4$ ). They also reported positive perceptions of neighbourhood safety (mean $=0 \cdot 64, \mathrm{sD}=$ $0 \cdot 76$ ) and pleasantness (mean $=0 \cdot 76, \mathrm{sD}=0 \cdot 99)$. A majority of parents reported that it was a rule in the household that the adolescent had to participate in some kind of sports $(66 \%)$ and $59 \%$ of the parents themselves participated in leisure-time sports activities.

\section{Associations between environmental factors and theory of planned bebaviour variables}

Multivariate analyses showed that most of the physical and social environmental variables were significantly positively associated with TPB variables (Table 2). No associations were found for neighbourhood facilities with attitude, perceived behaviour control and intention. PA attributes at home and neighbourhood safety were not associated with perceived behaviour control. Parents' sports behaviour was not associated with subjective parental norm.

\section{Associations of theory of planned behaviour variables with adolescents' leisure-time sports participation}

To establish a mediation effect, the potential mediators must be associated with the outcome variable after adjustment for independent environmental variables ${ }^{(28)}$. Multivariate analyses (Table 3 ) showed that attitude and intention were found to be significantly associated with a higher likelihood of participating in leisure-time sports after adjustment for physical environmental variables (attitude $\mathrm{OR}=2 \cdot 30$; intention $\mathrm{OR}=2 \cdot 10$ ) and after adjustment for social environmental variables (attitude $\mathrm{OR}=2 \cdot 24$; intention $\mathrm{OR}=2 \cdot 03$ ).

\section{Mediating effects of theory of planned bebaviour variables}

As neighbourhood facilities were not associated with attitude and intention, this factor was not included in the mediation models (Table 4). The association of PA attributes 
Table 1 Behavioural, demographic, cognitive and environmental characteristics of the ENDORSE study population $(n 584)$

\begin{tabular}{|c|c|c|c|}
\hline Variables & Mean or \% & SD & Range \\
\hline \multicolumn{4}{|l|}{ Behaviour } \\
\hline Sports participation ( $\geq 30 \mathrm{~min} /$ week; $\%$ ) & $59 \cdot 8$ & - & - \\
\hline \multicolumn{4}{|l|}{ Demographics } \\
\hline Gender (girls; \%) & $45 \cdot 2$ & - & - \\
\hline Ethnicity (non-Western; \%) & $36 \cdot 6$ & - & - \\
\hline Age (years) & $13 \cdot 91$ & $1 \cdot 13$ & $11 \cdot 9$ to $17 \cdot 6$ \\
\hline Educational level (vocational schools; \%) & $49 \cdot 1$ & - & - \\
\hline \multicolumn{4}{|l|}{ Individual cognitions } \\
\hline Attitude & $1 \cdot 29$ & 0.64 & -2 to 2 \\
\hline Subjective parental norm & 1.50 & $0 \cdot 61$ & -2 to 2 \\
\hline Perceived behaviour control & $1 \cdot 12$ & $0 \cdot 81$ & -2 to 2 \\
\hline Intention & 1.57 & $0 \cdot 79$ & -2 to 2 \\
\hline \multicolumn{4}{|l|}{ Physical environment } \\
\hline PA attributes at home & 3.97 & $2 \cdot 08$ & 0 to 10 \\
\hline Neighbourhood safety & 0.64 & $0 \cdot 76$ & -2 to 2 \\
\hline Neighbourhood pleasantness & $0 \cdot 76$ & 0.99 & -2 to 2 \\
\hline Neighbourhood facilities & $3 \cdot 26$ & 0.95 & 0 to 4 \\
\hline \multicolumn{4}{|l|}{ Socio-cultural environment } \\
\hline Parental rule to play sports (yes; \%) & $65 \cdot 8$ & - & - \\
\hline Parent behaviour (parent does practice sports; \%) & $59 \cdot 4$ & - & - \\
\hline
\end{tabular}

ENDORSE, ENvironmental Determinants of Obesity in Rotterdam SchoolchildrEn; PA, physical activity.

Table 2 Results of multivariate linear regression analyses (unstandardized regression coefficients) of physical and social environmental variables with TPB variables as dependent variables, adjusted for age, gender, ethnicity, school type and clustering within classes and schools

\begin{tabular}{|c|c|c|c|c|}
\hline & Attitude & $\begin{array}{c}\text { Subjective } \\
\text { parental norm }\end{array}$ & $\begin{array}{l}\text { Perceived behaviour } \\
\text { control }\end{array}$ & Intention \\
\hline PA attributes at home & $0.039^{\star \star}$ & $0.042^{\star \star}$ & 0.026 & $0.056^{\star \star \star}$ \\
\hline Neighbourhood safety & $0 \cdot 146^{\star \star \star}$ & $0 \cdot 120^{\star \star *}$ & 0.016 & $0 \cdot 186^{* * *}$ \\
\hline Neighbourhood pleasantness & $0 \cdot 168^{\star \star \star}$ & $0 \cdot 090^{\star \star \star}$ & $0 \cdot 105^{\star \star}$ & $0 \cdot 115^{\star \star \star}$ \\
\hline Neighbourhood facilities & 0.035 & $0.059^{\star \star}$ & 0.028 & 0.049 \\
\hline Parental rule & $0 \cdot 141^{*}$ & $0 \cdot 121^{*}$ & $0 \cdot 174^{\star}$ & $0 \cdot 166^{\star}$ \\
\hline Parent behaviour & $0 \cdot 135^{*}$ & -0.001 & $0 \cdot 185^{\star \star}$ & $0 \cdot 180^{\star *}$ \\
\hline
\end{tabular}

TPB, theory of planned behaviour; PA, physical activity.

${ }^{\star} P<0.05 ;{ }^{* \star} P<0.01 ;{ }^{\star \star *} P<0.001$.

Table 3 Results of multivariate logistic regression analysis (OR) examining the association between potential mediators (TPB variables) and leisure-time sports participation ( $\geq 30 \mathrm{~min})$, adjusting for the physical (Model 1) and social (Model 2) environmental factorst

\begin{tabular}{|c|c|c|c|c|}
\hline & \multicolumn{2}{|c|}{ Model 1} & \multicolumn{2}{|c|}{ Model 2} \\
\hline & OR & $95 \% \mathrm{Cl}$ & OR & $95 \% \mathrm{Cl}$ \\
\hline \multicolumn{5}{|l|}{ Physical environmental factors } \\
\hline PA attributes at home & $1 \cdot 20$ & $1 \cdot 07,1 \cdot 35$ & - & - \\
\hline Neighbourhood safety & $1 \cdot 22$ & $0.86,1.73$ & - & - \\
\hline Neighbourhood pleasantness & $0 \cdot 89$ & $0 \cdot 68,1 \cdot 16$ & - & - \\
\hline PA facilities in the neighbourhood & $1 \cdot 02$ & $0 \cdot 83,1 \cdot 23$ & - & - \\
\hline \multicolumn{5}{|l|}{ Socio-cultural environmental factors } \\
\hline Parental rule & - & - & $1 \cdot 37$ & $0 \cdot 85,2 \cdot 20$ \\
\hline Parents sports behaviour & - & - & $1 \cdot 79$ & $1 \cdot 14,2 \cdot 80$ \\
\hline \multicolumn{5}{|l|}{ TPB variables } \\
\hline Attitude & $2 \cdot 30$ & $1 \cdot 46,3 \cdot 61$ & $2 \cdot 24$ & $1 \cdot 48,3 \cdot 39$ \\
\hline Parental norm & $1 \cdot 21$ & $0 \cdot 82,1 \cdot 80$ & $1 \cdot 29$ & $0.87,1.92$ \\
\hline Perceived behaviour control & $1 \cdot 00$ & $0 \cdot 76,1 \cdot 33$ & 0.96 & $0 \cdot 72,1 \cdot 27$ \\
\hline Intention & $2 \cdot 10$ & $1 \cdot 47,3 \cdot 02$ & 2.03 & $1 \cdot 42,2 \cdot 91$ \\
\hline
\end{tabular}

TPB, theory of planned behaviour; PA, physical activity.

tMultivariate logistic regression analyses adjusted for age, gender, ethnicity, school type and clustering within classes and schools.

at home with a higher likelihood of participating in leisure-time sports was partly mediated by attitude $(17 \cdot 4 \%)$ and intention $(21.6 \%)$, as indicated by the significant
Sobel test results. The association between neighbourhood safety and sports participation was significantly mediated by intention; however, both direct and indirect 
associations were not significant. The direction of the association between neighbourhood pleasantness and sports participation changed after adjustment for attitude, which suggests an inconsistent mediation model.

The associations of parental rule and parents' sports behaviour with a higher likelihood of participating in leisure-time sports were also partly mediated by attitude and intention with percentages ranging between $20 \cdot 1$ and $31 \cdot 7$ (Table 5). The associations of PA attributes at home and parent behaviour with leisure-time sports remained statistically significant, while the association of parental rule lost significance in the mediation models.

\section{Discussion}

In the present study, associations of socio-cultural and physical environmental factors with adolescents' leisuretime sports participation were examined and it was explored whether these associations were mediated by individual cognitions such as attitudes and intentions. Results showed that parents' sports behaviour, parental rule about sports behaviour and availability of PA attributes at home were associated with a higher likelihood that adolescents engaged in sports behaviour. We cannot draw conclusions on the findings that resulted from an inconsistent mediation model ${ }^{(33)}$. The inconsistent model is a result of the fact that the direct association between neighbourhood pleasantness and sports participation was weak but positive, while the indirect association was also weak and non-significant, but negative.

Evidence was found for the partial mediation of social and physical environmental factors by attitude and intention. However, a direct significant association also remained of PA attributes at home and parental behaviour with leisure-time sports participation. These findings are in accordance with those of earlier studies in which attitudes were found to be strong mediators of the association between physical environmental factors and $\mathrm{PA}^{(15-17,19,20)}$. The results suggest that both direct, automatic influences of the environment and more reasoned cognitive processes are important in adolescents' sports participation as suggested in the EnRG framework ${ }^{(9)}$. However, as we found rather strong associations of attitude and intention with leisure-time sports participation in the present study, adolescents' leisure-time sports behaviour seems to be, at least partly, also the result of a more reasoned, deliberate process that is not influenced by the environmental factors considered in the present study. This does make sense, since sports activities are less likely to be part of routine habits, more likely needing to be planned in advance and to be dependent on explicit positive motivation than, for example, daily activities. The present results support this hypothesis to a certain extent, as we found significant but small correlations between environmental factors and cognitions. This association of 
cognitions, independent of the environmental factors, is not clearly stated in the EnRG framework that focuses on cognitions as mediators of environmental influences. Two of the four cognitions included in the present study, i.e. parental subjective norm and perceived behavioural control, were not found to be associated with sports behaviour. This might indicate that not all cognitions as suggested by the TPB are important mediators or play a role in the suggested reasoned process for this particular behaviour in this population group. On the other hand, the non-significant results might be caused by the limited assessment of these constructs with only one or two items.

In accordance with other studies, social factors seem to be more strongly associated with PA behaviour than physical environmental factors ${ }^{(12-14)}$. The direct associations of parents' sports behaviour and the availability of PA equipment at home support earlier evidence that parental example and support (for instance, through providing good sports equipment at home) are important for PA promotion. The range of social factors considered in the present study was narrow, and factors such as social networks, friends' support and behaviour and the perceived behaviour of parents should be included in future studies to provide further insight into specific aspects of the social environment that are most important for adolescents' PA behaviours ${ }^{(18,34)}$. Next to this, future research should address the moderating effects of sociodemographic factors mentioned in the EnRG framework as there are clear gender differences in sports participation and correlates of PA might be different for boys and girls. For example, mothers' PA appears to be more often associated with girls' rather than boys' physical activity ${ }^{(12)}$.

One possible limitation of the present study was that we used perceptions of the environment instead of more objective measures of the physical environment. Perceived environmental factors are, of course, also cognitive representations (i.e. of environmental factors), and different mediating pathways may be apparent with more objective assessments of the environment. Evidence points out that perceived and objective environmental factors are different constructs ${ }^{(35)}$ and that perceptions of the environment only partly depend on what is objectively available in the environment ${ }^{(36)}$. Studies exploring TPB variables as well as perceived environmental factors as mediators of the associations between objective environmental characteristics and PA behaviour may help to unravel the interplay between individual and environmental factors in influencing energy balance-related behaviours as proposed in the EnRG framework.

The following limitations should be taken into account when interpreting the results of the present study. The cross-sectional design of the study did not allow us to determine causal effects and is an important limitation in research examining mediation pathways. Physically active adolescents might be more aware of PA equipment in their environment and they might select more or less 
the neighbourhood they are active in by having a specific definition about how large the neighbourhood is. Having positive cognitions towards sports might shape the adolescents' environment. For instance, adolescents might influence their parents by promoting sports activities and asking for more equipment. Next to this, the sample size of the present study was restricted because of the rather low response rate for the parent questionnaire. The fact that adolescents from a non-Western ethnic background and lower educational level were underrepresented in the sample suggests a selection bias. Several limitations relate to the measurement instruments used in the study.

First, adolescents' sports behaviour was based on selfreport and in a validation study with the use of accelerometers it was shown that the questionnaire had limited validity and that adolescents over-reported their activity levels ${ }^{(22)}$. Second, the TPB variables were assessed with only one or two items leading to limited reliability. The TPB variables, particularly perceived behaviour control, might not have been robust enough to show associations and to show up as a mediator. Environmental constructs were often measured with only one or two items with only moderate reliability. In explorative research, more effort needs to be made to construct better scales that examine all aspects of the perceived environmental factors. More qualitative research is needed to improve the existing measurement instruments and scales. Next to this, only a limited set of perceived environmental variables was used in the present study. Other social environmental influences such as encouragement of parents and friends might especially be important in explaining PA behaviours ${ }^{(12,14,37)}$. Parents' sports behaviour was also assessed with other questions compared to adolescents' sports participation, and other cut-off points were used. This could also have affected the associations found. Third, adolescents with overweight or lack of PA might have given socially desirable answers on sports behaviour and on the TPB items as well, which could have influenced the associations between cognitions and behaviour. Nevertheless, this explorative study contributes to the structured examination of the associations between environmental factors and PA and the suggested mediation by TPB variables as supposed by the EnRG framework.

\section{Conclusion}

Dutch adolescents were more likely to engage in leisuretime sports when PA attributes were available at home, when parents participated in sports activities and had the rule in their household that the child has to play a sport. These associations were partly mediated by attitude and intention. This indicates that parents are important actors in shaping the environmental factors of interest by making sports activities accessible and a family routine. Therefore, not only adolescents, but also parents should be targeted in interventions aiming to improve PA among adolescents. However, the cross-sectional design of the present study should be taken into account and the findings have to be verified in longitudinal and experimental studies. Efforts need to be made construct better measurement instruments and scales to examine perceived environmental factors.

\section{Acknowledgements}

Sources of funding: The present study was supported by grants from ZonMw, the Netherlands Organization for Health Research and Development (Grant no. 2100.0103) and The World Cancer Research Fund - WCRF-NL (Grant no. 2007/47). The present paper has been facilitated by the EU-funded HOPE project: 'Health-promotion through Obesity Prevention across Europe (the Commission of the European Communities, SP5A-CT-2006-044128). The study does not necessarily reflect the Commission's views and in no way anticipates the Commission's future policy in this area', and was part of CEPHIR: the Center for Effective Public Health in the larger Rotterdam Area. Conflicts of interest declaration: The authors had no conflicts of interest in writing this paper. Authorship responsibilities: K.v.d.H. supervised the data collection, analysed the data and wrote most of the paper. S.J.t.V. contributed to the data analyses and provided feedback on the manuscript. A.O. and J.B. contributed to the study set-up, the design of the paper and provided feedback on the manuscript.

\section{References}

1. Boreham C \& Riddoch C (2001) The physical activity, fitness and health of children. J Sports Sci 19, 915-929.

2. Wareham NJ, van Sluijs EM \& Ekelund U (2005) Physical activity and obesity prevention: a review of the current evidence. Proc Nutr Soc 64, 229-247.

3. Lampert T, Mensink GB, Romahn N et al. (2007) [Physical activity among children and adolescents in Germany. Results of the German Health Interview and Examination Survey for Children and Adolescents (KiGGS)] Korperlichsportliche Aktivitat von Kindern und Jugendlichen in Deutschland. Ergebnisse des Kinder- und Jugendgesundheitssurveys (KiGGS). Bundesgesundheitsblatt Gesundheitsforschung Gesundheitsschutz 50, 634-642.

4. Scully M, Dixon H, White V et al. (2007) Dietary, physical activity and sedentary behaviour among Australian secondary students in 2005. Health Promot Int 22, 236-245.

5. Tammelin T, Ekelund U, Remes J et al. (2007) Physical activity and sedentary behaviors among Finnish youth. Med Sci Sports Exerc 39, 1067-1074.

6. Centers for Disease Control and Prevention (2006) Youth Risk Behavior Surveillance - United States. MMWR Surveill Summ 55, Suppl. 5, 1-112.

7. Telama R, Yang X, Viikari J et al. (2005) Physical activity from childhood to adulthood: a 21-year tracking study. Am J Prev Med 28, 267-273.

8. Ajzen I (1991) The theory of planned behavior. Organ Behav Hum Dec 50, 179-211. 
9. Kremers SP, De Bruijn GJ, Visscher TL et al. (2006) Environmental influences on energy balance-related behaviors: a dual-process view. Int J Behav Nutr Phys Act 15: 9.

10. Sallis JF \& Owen N (2002) Ecological models of health behavior. In Health Behavior and Health Education, 3rd ed., pp. 462-485 [K Glanz, BK Rimer and FM Lewis, editors]. San Fransisco, CA: Jossey-Bass.

11. Stokols D (1992) Establishing and maintaining healthy environments. Toward a social ecology of health promotion. Am Psychol 47, 6-22.

12. Ferreira I, van der Horst K, Wendel-Vos W et al. (2007) Environmental correlates of physical activity in youth - A review and update. Obes Rev 8, 129-154.

13. Sallis JF, Prochaska JJ \& Taylor WC (2000) A review of correlates of physical activity of children and adolescents. Med Sci Sports Exerc 32, 963-975.

14. Van Der Horst K, Chin a Paw MJ, Twisk JW et al. (2007) A brief review on correlates of physical activity and sedentariness in youth. Med Sci Sports Exerc 3, 1241-1250.

15. Rhodes RE, Brown SG \& McIntyre CA (2006) Integrating the perceived neighborhood environment and the theory of planned behavior when predicting walking in a Canadian adult sample. Am J Health Promot 21, 110-118.

16. Rhodes RE, Courneya KS, Blanchard CM et al. (2007) Prediction of leisure-time walking: an integration of social cognitive, perceived environmental, and personality factors. Int J Behav Nutr Phys Act 4: 51.

17. de Bruijn GJ, Kremers SP, Lensvelt-Mulders G et al. (2006) Modeling individual and physical environmental factors with adolescent physical activity. Am J Prev Med 30, 507-512.

18. Motl RW, Dishman RK, Saunders RP et al. (2007) Perceptions of physical and social environment variables and selfefficacy as correlates of self-reported physical activity among adolescent girls. J Pediatr Psychol 32, 6-12.

19. Van der Horst K, Timperio A, Crawford D et al. (2008) The school food environment: associations with adolescent soft drink and snack consumption. Am J Prev Med 35, $217-223$.

20. van der Horst K, Kremers S, Ferreira I et al. (2007) Perceived parenting style and practices and sugar-sweetened beverage consumption in adolescents. Health Educ Res 22, 295-304.

21. van der Horst $\mathrm{K}$, Oenema A, van de Looij-Jansen $\mathrm{P}$ et al. (2008) The ENDORSE study: research into environmental determinants of obesity related behaviors in Rotterdam schoolchildren. BMC Public Health 8: 142.

22. Slootmaker SM, Schuit AJ, Chinapaw MJ et al. (2009) Disagreement in physical activity assessed by accelerometer and self-report in subgroups of age, gender, education and weight status. Int J Behav Nutr Phys Act 6, 17 .

23. Norm Gezond Bewegen (2010) http://www.kiesbeter. $\mathrm{nl} /$ gezondleven/bewegen/norm\%2Dgezond\%2Dbewegen/ (accessed April 2010).

24. Sallis JF, Johnson MF, Calfas KJ et al. (1997) Assessing perceived physical environmental variables that may influence physical activity. Res Q Exerc Sport 68, 345-351.

25. Wendel-Vos GC, Schuit AJ, Saris WH et al. (2003) Reproducibility and relative validity of the short questionnaire to assess health-enhancing physical activity. J Clin Epidemiol 56, 1163-1169.

26. Statistics Netherlands (2010) http://www.cbs.nl/nl-NL/menu/ methoden/begrippen/default.htm (accessed April 2010).

27. MacKinnon DP (2008) Introduction to Statistical Mediation Analysis. New York: Lawrence Erlbaum Associates, Taylor \& Francis Group, LLC.

28. Cerin E \& MacKinnon DP (2008) A commentary on current practice in mediating variable analyses in behavioural nutrition and physical activity. Public Health Nutr 9, 1-7.

29. Twisk JWR (2006) Applied Multilevel Analysis: A Practical Guide. New York: Cambridge University Press.

30. MacKinnon DP, Lockwood CM, Brown CH et al. (2007) The intermediate endpoint effect in logistic and probit regression. Clin Trials 4, 499-513.

31. Jasti S, Dudley WN \& Goldwater E (2008) SAS macros for testing statistical mediation in data with binary mediators or outcomes. Nurs Res 57, 118-122.

32. Baron RM \& Kenny DA (1986) The moderator-mediator variable distinction in social psychological research: conceptual, strategic, and statistical considerations. J Pers Soc Psychol 51, 1173-1182.

33. MacKinnon DP, Krull JL \& Lockwood CM (2000) Equivalence of the mediation, confounding and suppression effect. Prev Sci 1, 173-181.

34. Brug J, Kremers SP, van Lenthe F et al. (2008) Environmental determinants of healthy eating: in need of theory and evidence. Proc Nutr Soc 67, 307-316.

35. McGinn AP, Evenson KR, Herring AH et al. (2007) Exploring associations between physical activity and perceived and objective measures of the built environment. J Urban Health 84, 62-84.

36. Scott MM, Evenson KR, Cohen DA et al. (2007) Comparing perceived and objectively measured access to recreational facilities as predictors of physical activity in adolescent girls. J Urban Health 84, 346-359.

37. Hohepa M, Scragg R, Schofield G et al. (2007) Social support for youth physical activity: Importance of siblings, parents, friends and school support across a segmented school day. Int J Behav Nutr Phys Act 4: 54. 